\title{
Hearing Impairment in Female Carriers of the Sex-linked Syndrome of Deafness with Albinism
}

\author{
K. FRIED, M. FEINMESSER, and J. TSITSIANOV \\ From the Department of Human Genetics and Laboratory of Genetics, and the Department of E.N.T., Hadassah \\ University Hospital, ferusalem, Israel
}

A family which is part of a large kindred in which a sex-linked recessive syndrome manifested by profound deafness and partial albinism was reported by Margolis (1962) and independently by Ziprkowski et al. (1962). According to their reports hearing impairment was not found in carriers.

The family first came to our attention because of deafness of a male child (III.5, Fig. 1) and later for genetic counselling when his mother (II.1) became pregnant. She did not admit hearing loss, but a routine audiometry disclosed a severe sensorineural deafness on the left side, which was moderate on the right. Because of this finding in a genetically proven carrier, we examined other female members of the family who were unaware of hearing loss, and more cases with hearing impairment were detected. They are reported here.

\section{Audiological Findings}

In four female members of the family (three generations), bilateral impairment of hearing of

Received June 4, 1968. sensorineural type was detected by audiometric tests (Fig. 2). In one (I.1) the hearing loss was severe in both ears, in two others (II.1 and III.3) it was severe or profound in the left ear and moderate or mild in the right ear; the hearing loss was moderate bilaterally in the fourth case (III.1).

Another female member of the family (II.8) showed a moderate hearing loss of mixed type on the right side only, but this could be considered due to chronic suppurative otitis media on this side.

Vestibular caloric tests in two of the four female members with hearing impairment (II.1 and III.3) were within normal limits.

\section{Discussion}

This family with its peculiar syndrome is apparently still unique. Fraser (1965) suggested that the two Indian brothers reported by Woolf (1965) might have the same syndrome. However, from the published photographs, it is apparent that the brothers had large areas of normally pigmented skin, while Ziprkowski et al. (1962) found that 'The

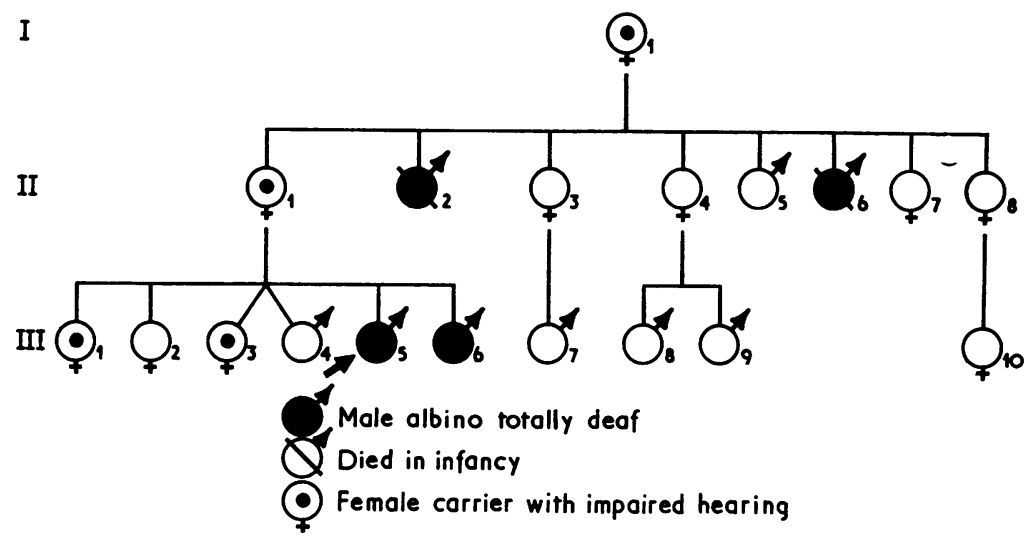

Fig. 1. Pedigree of family. All living persons except II.5 were examined personally by audiometry. III. 5 in this paper = V. 74 in Margolis (1962) =V. 51 in Ziprkowski et al. (1962). 

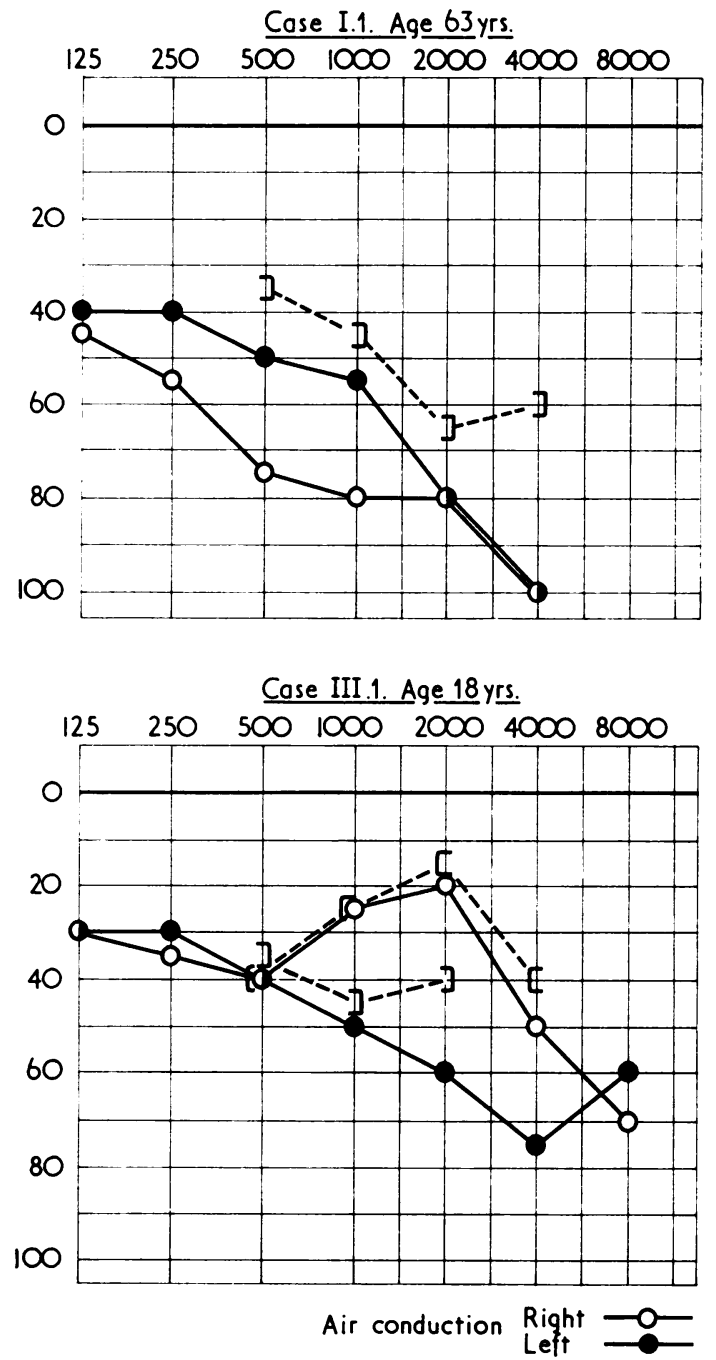
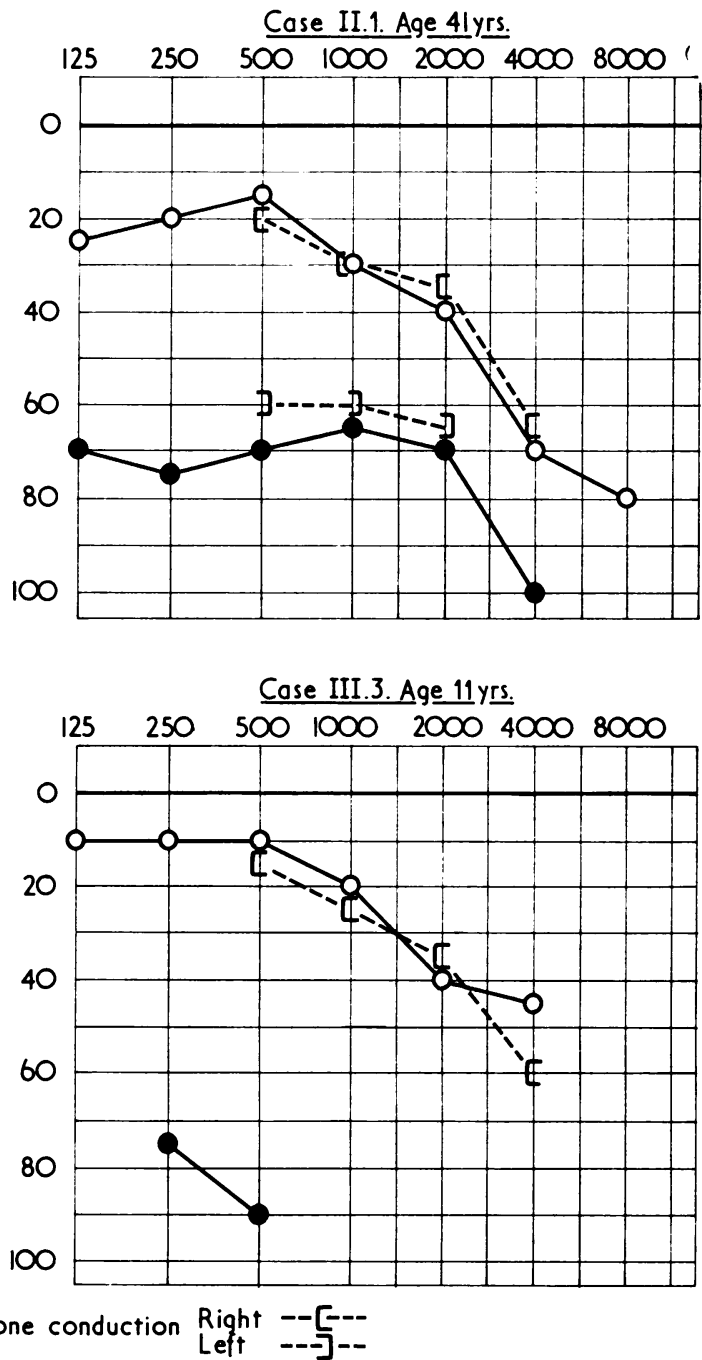

FIG. 2. Pure tone audiograms of female carriers.

skin was either hyper- or hypopigmented with no other normal areas whatsoever'-a finding well seen in one of our cases (see Fig. 3). Margolis (1962) called the pigmentary changes total albinism because of the absence of normally pigmented skin, and Ziprkowski et al. (1962) preferred to name it partial albinism because of the large areas of hyperpigmented skin. Perhaps the syndrome could best be named as albinism with hyperpigmented areas and deaf mutism.

There are only a few reported kindreds with sexlinked hereditary deafness. In these families deafness is not associated with any other pathological changes. Sataloff, Pastore, and Bloom (1955) did not publish audiograms of carrier females. Audiograms of female heterozygotes of the family reported by Parker (1958) showed no tendency of partial expression of the gene. Normal hearing was found in a female heterozygote reported by Fraser (1965) (though it is not stated explicitly that she was tested by audiometry). Audiometry is obviously desirable in all carriers of sex-linked recessive deafness.

The syndrome described by Klein (1950) and by Waardenburg (1951) and named after them can be differentiated from that in the present report. In the Klein-Waardenburg syndrome there are anatomical changes in the face, including lateral displace- 


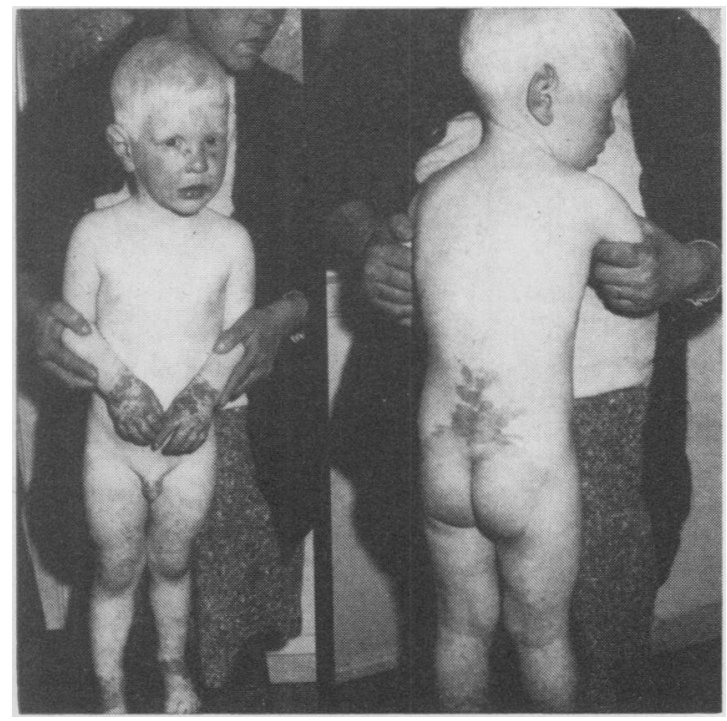

FIG. 3. Front and back view of affected male III.6. Note absence of normally pigmented skin in the son and the normally pigmented skin of the carrier mother II.1. (Only her hands and part of her face are seen in the picture.)

ment of the medial canthi. Both sexes are equally affected and transmission is in an irregularly dominant autosomal manner.

That we are dealing with a sex-linked recessive disease was suggested by Margolis (1962) and by Ziprkowski et al. (1962), but the latter also offered an alternative and less likely hypothesis, that the disease was transmitted by an autosomal dominant gene sex limited to the male. The present pedigree (in a distant branch not shown here), which records two normal males born to an affected father, leaves the question open. On either hypothesis there are carrier females, and it seems that it is possible to detect the carrier state in women by hearing tests. Audiometry detected the two genetically proven carriers (I.1 and II.1) and revealed two more (III.1 and III.3) out of seven possible carriers. It is not yet known whether all carriers could be detected by such tests.

\section{Summary}

Two genetically proven female carriers of the gene for deafness and albinism as well as two out of seven possible carriers were found to have hearing impairment of sensorineural type. The hearing impairment was detected by audiometry.

\section{REFERENCES}

Fraser, G. R. (1965). Sex-linked recessive congenital deafness and the excess of males in profound childhood deafness. Ann. hum. Genet., 29, 171.

Klein, D. (1950). Albinisme partiel (leucisme) avec surdi-mutité, blépharophimosis et dysplasie myo-ostéo-articulaire. Helv. paediat. Acta, 5, 38.

Margolis, E. (1962). A new hereditary syndrome-sex-linked deafmutism associated with total alminism. Acta. genet. (Basel), 12, 12.

Parker, N. (1958). Congenital deafness due to a sex-linked recessive gene. Amer. F. hum. Genet., 10, 196.

Sataloff, J., Pastore, P. N., and Bloom, E. (1955). Sex-linked hereditary deafness. ibid., 7, 201.

Waardenburg, P. J. (1951). A new syndrome combining developmental anomalies of the eyelids, eyebrows, and nose root with pigmentary defects of the iris and head hair and with congenital deafness. ibid., 3, 195.

Woolf, C. M. (1965). Albinism among Indians in Arizona and NewMexico. ibid., 17, 23.

Ziprkowski, L., Krakowski, A., Adam, A., Costeff, H., and Sade, J. (1962). Partial albinism and deafmutism due to a recessive sexlinked gene. Arch. Derm., 86, 530.

\section{Addendum}

After this paper was submitted, on November 3, 1968, II.8 gave birth to an albino son who did not react to auditory stimuli. This proved II.8 to be a female carrier. 